\title{
Quantity of hydrophobic functional CH-groups - decisive for soil water repellency caused by digestate amendment
}

\author{
Amrei Voelkner ${ }^{*}$, Dörthe Holthusen ${ }^{1}$, Ruth H. Ellerbrock ${ }^{2}$, and Rainer Horn ${ }^{1}$ \\ ${ }^{1}$ Institute of Plant Nutrition and Soil Science, University of Kiel, Hermann-Rodewald 2, 24118 Kiel, Germany \\ ${ }^{2}$ Institute of Soil Landscape Research, Leibnitz Centre for Agricultural Landscape Research, Eberswalder 84, \\ 15374 Müncheberg, Germany
}

Received November 6, 2014; accepted February 26, 2015

\begin{abstract}
A b s t r a c t. Anaerobic digestates are used as organic fertilizers; however, they are suspected to interfere negatively with soils. To investigate the relevance of the anaerobic digestates composition on potential wettability and contact angle of the soil, we mixed in a laboratory experiment $30 \mathrm{~m}^{3} \mathrm{ha}^{-1}$ of anaerobic digestates derived from mechanically pre-treated substrates from maize and sugar beet with a homogenized Cambic Luvisol. Fourier transform infrared-spectra and diffuse reflectance infrared Fourier transform-spectra of particle intact and finely ground soilanaerobic digestates-mixtures were analyzed to determine the quantities of hydrophobic functional groups in the soil-anaerobic digestates-mixtures that are used here as an indicator for the potential hydrophobicity. The anaerobic digestates application increased the amount of hydrophobic functional groups of the mixtures and reduced the wettability of the soil. However, for intact particle samples an up to threefold higher amount of hydrophobic groups was found as compared to the finely ground ones, indicating a dilution effect of mechanical grinding on the effectivity of the organic matter that is presumably located as a coating on mineral soil particles. For the particle intact samples, the intensity of hydrophobic functional groups bands denoting hydrophobic brickstones in organic matter is indicative for the actual wettability of the soil-anaerobic digestates-mixtures.

$\mathrm{K}$ e y w o r d s: anaerobic digestates, organic matter composition, Fourier transform infrared spectroscopy, diffuse reflectance infrared Fourier transform spectroscopy
\end{abstract}

\section{INTRODUCTION}

Responding to the financial compensation for generating renewable energy, the installation of biogas plants on arable land increased in recent years. Anaerobic digestates (AD) are a by-product of biogas generation by anaerobic fermentation. Application of AD on agricultural soils will

*Corresponding author e-mail: a.voelkner@soils.uni-kiel.de **This work was funding by the Fachagentur für nachwachsende Rohstoffe (FKZ 22401312), 2012-2015. influence the intrinsic soil organic matter pools, due to their organic carbon contents (Boyd et al., 1980). Additionally, it will enhance the fertility of soils (Réveillé et al., 2003) due to their vast amounts of plant nutrients (Alburquerque et al., 2012) like plant available ammonium, potassium, and phosphorus (Sørensen and Møller, 2009). Besides these positive properties, digestates are suspected to have negative impacts on soils since they transfer recalcitrant amphiphilic substances (eg humic, fulvic, and fatty acids) into the soil matrix. Such amphiphilic substances cover soil particle surfaces, resulting in modification of the physicochemical properties of soils (Hurraß and Schaumann, 2006). The term amphiphilic substances describes molecules formed by both, hydrophobic and hydrophilic functional groups (Morrison and Boyd, 1983), which altogether may affect the actual wettability of soils (Franco et al., 2000). Soil organic matter (OM) consists of amphiphilic components; therefore, Negre et al. (2002) linked the ability of water to spread on a soil surface to the macromolecular composition of OM. In consequence, the wetting behaviour of soils may change with the content and composition of OM coatings on mineral particle surfaces (Leue et al., 2010) as well as the spatial arrangement of OM compounds at the molecular scale (Morrison and Boyd, 1983). Spectroscopic techniques like Fourier transmission infrared (FTIR) and diffuse reflection infrared Fourier transform (DRIFT) spectroscopy have been widely used to characterize the composition of functional groups in soil organic matter (SOM) (Capriel et al., 1995; Gerzabek et al., 1997; Tatzber et al., 2007) and at intact aggregate surfaces (Leue et al., 2010 ) in order to determine the potential wettability of OM.

(C) 2015 Institute of Agrophysics, Polish Academy of Sciences 
The hydrophobic functional groups of OM are represented by methylene and methyl groups $(\mathrm{CH})$, whereas carboxyl- and hydroxyl $(\mathrm{C}=\mathrm{O})$ groups reflect the hydrophilic ones. Characteristic absorption bands in FTIR and DRIFT spectra allow analysis of the contents of hydrophobic $\mathrm{CH}-$ (Capriel, 1992) and hydrophilic $\mathrm{C}=\mathrm{O}$-groups (Celi et al., 1997). Thus, such spectroscopy techniques (FTIR Demyan et al., 2012; DRIFT eg Reeves et al., 2001) have been widely applied to characterize the OM composition. Celi et al. (1997) stated the $\mathrm{CH} / \mathrm{C}=\mathrm{O}$ ratio should be appropriate to deduce the potential hydrophobic properties of the OM (Morrison and Boyd, 1983), while Ellerbrock et al. (2005) could not detect reduced wettability with an increasing $\mathrm{A} / \mathrm{B}$ ratio. They justified these findings with the low effectiveness of the hydrophobic CH-bands to cause wettability. These results however also prove that the effectiveness of the quantity of $\mathrm{CH}$-bands within $\mathrm{OM}$ originating from $\mathrm{AD}$ on the hydrophobicity in soils is still unknown. Since soil hydrophobicity results in severe ecological problems such as soil erosion, especially in sloped areas, it would be necessary to investigate the causes of this process.

Therefore, the aim of the study was to evaluate the consequences of the application of $\mathrm{AD}$ different in $\mathrm{OM}$ composition on the wettability of soil mineral surfaces. We assume that even a small amount of wetting-restraining $\mathrm{CH}$-groups will be sufficient to reduce the sample wettability and that, in this case, the effect of the $\mathrm{CH}$-groups dominates the effect of the hydrophilic $\mathrm{C}=\mathrm{O}$-groups. We hypothesize that the ratio between hydrophobic and hydrophilic groups is less effective in estimation of the impact of the $\mathrm{AD}$ application on the wetting behaviour of soils as compared to the intensity of $\mathrm{CH}$ absorption bands.

\section{MATERIALS AND METHODS}

For the laboratory measurements, disturbed soil material was sampled in June 2013 from the first $10 \mathrm{~cm}$ of the A-horizon of an arable Cambic Luvisol (derived from Weichselian glacial till, FAO, 1998) at the research farm Hohenschulen of the University of Kiel, Germany. The chemical parameters of the soil was analyzed using standard procedures according to Schlichting et al. (1995).

The soil sample $(\mathrm{n}=1)$ from Hohenschulen contained $166,272,1.2$, and $7 \mathrm{~g} \mathrm{~kg}^{-1}$ clay, silt, organic carbon, and nitrogen, respectively was classified as a sandy loam (FAO, 1998). The soil $\mathrm{pH}$ of 6.6 exhibited slightly acidic conditions and was classified as Cambic Luvisol (KA5, 2006).

Liquid digestates were produced at the Institute for Agricultural Engineering (University of Kiel) in batchfermentation processes. Input substrates (IS) from maize (Zea mays L.) and sugar beet (Beta vulgaris L.) were mechanically pre-treated by grinding (gr) or chopping (ch) and digested in monofermentation (one IS) and cofermentation (two IS in different ratios) (Table 1).
T a b l e 1. Summary of the mechanical pre-treatment (chchopped, gr-ground) and the ratio of the used input substrate (IS)

\begin{tabular}{|c|c|c|c|}
\hline Amendment & $\begin{array}{l}\text { Pre- } \\
\text { treatment }\end{array}$ & Input substrate & Ratio (\%) \\
\hline gr-M100 & ground & maize & 100 \\
\hline ch-M100 & chopped & & 100 \\
\hline gr-SB100 & ground & sugar beet & 100 \\
\hline ch-SB100 & chopped & & 100 \\
\hline gr-SB80M20 & ground & sugar beet/ & $80 / 20$ \\
\hline ch-SB80M20 & chopped & maize & $80 / 20$ \\
\hline gr-M80SB20 & ground & $\begin{array}{l}\text { maize/ } \\
\text { sugar beet }\end{array}$ & $80 / 20$ \\
\hline ch-M80SB20 & chopped & $\begin{array}{l}\text { maize/ } \\
\text { sugar beet }\end{array}$ & $80 / 20$ \\
\hline
\end{tabular}

The disturbed soil material from the top layer of the ploughed soil surface was air-dried and sieved to $\leq 2 \mathrm{~mm}$. Assuming an average soil depth of $30 \mathrm{~cm}$ in accordance with the common agricultural practice, $480 \mathrm{~g}$ of the airdried soil were mixed with $30 \mathrm{ml}$ of anaerobic digestates (AD) (equivalent to $30 \mathrm{~m}^{3} \mathrm{ha}^{-1}$ ) by stirring. Additionally, a control treatment $(C)$ was prepared using the same amount of demineralized water instead of the digestates. Two mixtures (repetitions) of each treatment were prepared. The soil remained in contact with the $\mathrm{AD}$ for 10 days at $10^{\circ} \mathrm{C}$ until a biological equilibrium was reached. Then, the mixtures were again air-dried and homogenized. From each mixture, six subsamples were taken for determining the contact angle (CA), two for transmission FTIR and four for DRIFT measurements.

To determine the wetting behaviour, the CA of the air-dried soil samples $(\leq 2 \mathrm{~mm})$ was measured using the Wilhelmy-Plate-method (WPM) with a microtensiometer (Krüss, Hamburg, Germany) (Hartmann, 2008). The advancing and receding CA between 0 and $180^{\circ}$ was measured by immersing a glass plate covered with a one-grain layer of soil particles into distilled water with known surface tension. The $\mathrm{CA}(\cos \theta)$ was calculated from the force $\mathrm{F}(\mathrm{N})$ acting on the plate using Eq. (1):

$$
\cos \theta=F /\left(\rho \sigma_{L V}\right),
$$

where: $\sigma_{L V}\left(\mathrm{mN} \mathrm{m}^{-1}\right)$ denotes the surface tension of the liquid and $\rho$ indicates the liquid density $\left(\mathrm{g} \mathrm{cm}^{-3}\right)$. A CA between $0^{\circ}$ and $90^{\circ}$ characterises hydrophilic conditions, whereas values $\geq 90^{\circ}$ describe hydrophobic conditions (Bachmann et al., 2003). The measurement of the CA was conducted in six replicates per sample. 
The composition of the OM was characterized using transmission FTIR and DRIFT technique (Tremblay and Gagné, 2002). The functional groups of finely ground samples can be analyzed with both Fourier Transform Infrared spectroscopy (FTIR) (Haberhauer and Gerzabek, 1999) and the DRIFT technique. The DRIFT method has also been applied to detect the OM functional groups at the surface of intact soil particles (Leue et al., 2010):

- FTIR spectroscopy of ground samples $(\mathrm{G})$ mixed with potassium bromide (KBr),

- DRIFT spectroscopy of ground samples $(\mathrm{G})$,

- DRIFT spectroscopy of particle intact samples (PI).

For the FTIR measurements, air-dried samples from the soil-AD-mixtures $(\leq 2 \mathrm{~mm})$ and freeze-dried AD samples were finely ground in an agate mortar. For spectral analysis in the transmission technique FTIR, the $\mathrm{KBr}$ technique was used according to Capriel et al. (1992): one milligram of the ground samples was mixed with $80 \mathrm{mg} \mathrm{KBr}$. The mixture was dried over silica gel in an exsiccator for $12 \mathrm{~h}$ to standardize the water content of the samples, ground again in an agate mortar, and formed into a pellet using a hydraulic press $(9 \mathrm{t})$. The pellet was positioned into a sample holder.

For DRIFT measurements, the samples were either finely ground in an agate mortar $(\mathrm{G})$ or left particle intact (PI) (particles of $\leq 2 \mathrm{~mm}$ diameter) to analyze the effect of particle size distribution on the DRIFT signal intensities (Ellerbrock et al., 2009). One mg of the finely ground soildigestate-mixture was filled into cylindrical cups of $8 \mathrm{~mm}$ diameter and a height of $2 \mathrm{~mm}$. The PI samples from the soil-AD-mixtures were filled into a tinfoil box with $5 \mathrm{~cm}$ length and $1 \mathrm{~cm}$ width. The cups and box were placed on an aluminium plate, which was positioned on an XY-positioning table of the spectrometer (Leue et al., 2010). 32 internal scans with four replicates of the subsamples were recorded with a DRIFT device of the BioRad FTS 135 (BioRad Corp, Hercules, CA) in a range of wavenumber from 4000 to $400 \mathrm{~cm}^{-1}$ each spectra and corrected against ambient air as background (McDowell et al., 2012). The DRIFT spectra were recorded with a resolution of $4 \mathrm{~cm}^{-1}$ and 16 scans (16 repetitions of single spectra) (Ellerbrock and Kaiser, 2005). The spectra were smoothed with a boxcar function, which is unity within the interval and zero outside it and baseline-corrected using the software Win-IR Pro 3.4 (Digilab, Holliston, MA). Finally, the reflectance data were converted to Kubelka-Munk units using the standard KM transformation in the software to compare the adsorption intensity. The Kubelka-Munk equation relates the intensity of the reflected radiation to the concentration that can be used for quantitative evaluation. The KubelkaMunk function produces a transmission spectrum, which demonstrates a linear relationship between band intensity and the sample preparation. The Kubelka-Munk units are dimensionless.
The spectral interpretation focusses on absorption bands at $2920 \mathrm{~cm}^{-1}$ (asymmetric stretch) and $2860 \mathrm{~cm}^{-1}$ (symmetric stretch) caused by $\mathrm{CH}$-stretching vibrations of methyl and methylene groups (absorption band A) (Capriel et al., 1995). These groups represent the hydrophobic functional OM groups. The absorption bands characteristic for hydrophilic carboxylic $\mathrm{C}=\mathrm{O}$-groups (ie brickstones of ketones, carboxylic acids, or amides) occurred at 1701 to $1698 \mathrm{~cm}^{-1}$ (Günzler and Böck, 1990) (absorption band B). The cumulative heights of hydrophobic $\mathrm{CH}$-absorption bands were related to that of the hydrophilic $\mathrm{C}=\mathrm{O}$-bands ( $\mathrm{A} / \mathrm{B}$ ratio) in order to reflect the hydrophobic character of the $\mathrm{OM}$ (Ellerbrock et al., 2005) and to determine the potential wettability of the soil-AD-mixtures.

Statistical significance of the data was analyzed using the statistical software R (version 2.15.3). Based on the graphical residual analysis, the values were assumed to be normally distributed and heteroscedastic. Analysis of variance (ANOVA) was used to assess the statistical significance between the amendments and the control.

\section{RESULTS}

Both types of $\mathrm{AD}$ (mono and co-fermentation) as well as the $\mathrm{AD}$ obtained from monofermentation of ground input substrates (gr-M100 and gr-SB100) showed a pH $>8$ (Table 2). For the gr-M100 digestate, the highest ammonium content was found, while the digestates from monofermentation (ch-M100 and ch-SB100) and from cofermentation (gr-SB80M20 and gr-M80SB20) contained the highest amount of sodium ions compared to the other digestates.

The FTIR spectra indicated higher contents of hydrophobic $\mathrm{CH}$-groups for the $\mathrm{AD}$ derived from ground IS as compared to those of the chopped IS, but the $\mathrm{A} / \mathrm{B}$ ratio did not reflect such differences (Table 3). The DRIFT spectra of the AD samples showed strong signals due to light scattering caused by fibre particles contained in the AD. The signals resulting from direct scattering impeded the interpretation of the absorption bands of the $\mathrm{CH}-$ and $\mathrm{C}=\mathrm{O}$ groups in $\mathrm{OM}$.

The transmission FTIR and the DRIFT (Fig. 1a, b) spectra of the soil-AD-mixtures showed a similar peak pattern for $\mathrm{AD}$ from ground and chopped (graphic not shown) IS. The FTIR spectrum of the soil (control, C) sample indicated a maximum at $1100 \mathrm{~cm}^{-1}$ for the absorption band $\mathrm{C}$, while the soil-AD-mixtures exhibited a maximum at $1050 \mathrm{~cm}^{-1}$, indicating a change in the composition of polysaccharides that caused this absorption band. Such differentiation was not found in the DRIFT spectra of the corresponding samples. After application of digestates derived from ground IS, the amount of functional groups was significantly $(p<0.05)$ higher compared to the control.

All spectra exhibited absorption bands at 2920 to $2860 \mathrm{~cm}^{-1}$ due to $\mathrm{CH}$ vibrations of aliphatic methyl and methylene groups (band A) and at 1740 to $1698 \mathrm{~cm}^{-1}$ due 
T a b l e 2. Properties of the digestates obtained for ground (gr) and chopped (ch) input substrates ( $\mathrm{n}=1)$. Data expressed in $\%$ of the original substance (OS)

\begin{tabular}{|c|c|c|c|c|c|c|c|c|c|c|c|}
\hline \multirow{2}{*}{ Amendment } & \multirow{2}{*}{ 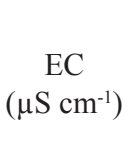 } & \multirow{2}{*}{$\mathrm{pH}$} & \multirow{2}{*}{$\begin{array}{l}\text { Acetic acid } \\
\left(\mathrm{g} \mathrm{kg}^{-1} \mathrm{OS}\right)\end{array}$} & $\begin{array}{c}\text { Dry } \\
\text { solids }\end{array}$ & $\mathrm{NH}_{4}-\mathrm{N}$ & Total N & $\mathrm{P}$ & $\mathrm{K}$ & $\mathrm{Mg}$ & $\mathrm{Ca}$ & \multirow{2}{*}{$\begin{array}{c}\mathrm{Na} \\
\left(\mathrm{mg} \mathrm{kg}^{-1} \mathrm{OS}\right)\end{array}$} \\
\hline & & & & \multicolumn{7}{|c|}{$(\%$ OS $)$} & \\
\hline gr-M100 & 81 & 8.25 & $<0.05$ & 2.8 & 0.21 & 0.24 & 0.23 & 0.03 & 0.02 & 0.02 & 139 \\
\hline ch-M100 & 83 & 7.93 & $<0.05$ & 3.0 & 0.14 & 0.24 & 0.27 & 0.04 & 0.03 & 0.03 & 179 \\
\hline gr-SB100 & 84 & 8.21 & $<0.05$ & 2.6 & 0.15 & 0.26 & 0.22 & 0.03 & 0.02 & 0.02 & 138 \\
\hline ch-SB100 & 82 & 7.85 & $<0.05$ & 2.8 & 0.13 & 0.23 & 0.25 & 0.03 & 0.03 & 0.02 & 167 \\
\hline gr-SB80M20 & 91 & 7.74 & 0.083 & 2.8 & 0.14 & 0.17 & 0.28 & 0.05 & 0.04 & 0.02 & 159 \\
\hline ch-SB80M20 & 85 & 7.82 & $<0.05$ & 2.9 & 0.14 & 0.26 & 0.23 & 0.03 & 0.02 & 0.02 & 140 \\
\hline gr-M80SB20 & 90 & 7.75 & $<0.05$ & 2.8 & 0.14 & 0.18 & 0.29 & 0.04 & 0.04 & 0.02 & 159 \\
\hline ch-M80SB20 & 87 & 7.85 & $<0.05$ & 3.2 & 0.15 & 0.25 & 0.24 & 0.04 & 0.02 & 0.02 & 145 \\
\hline
\end{tabular}

$<$ Below the detection limit.

T a b l e 3. Intensity of $\mathrm{CH}$ (band $\mathrm{A}$ ) and $\mathrm{C}=\mathrm{O}$ (band $\mathrm{B})$ in FTIR spectra $(\mathrm{n}=4)$ of freeze-dried digestates derived from ground $(\mathrm{gr})$ and chopped (ch) input substrate (IS)

\begin{tabular}{lccc}
\hline Amendment & $\mathrm{A}$ & $\mathrm{B}$ & $\mathrm{A} / \mathrm{B}$ \\
\hline gr-M100 & 0.108 & 0.505 & 0.215 \\
gr-SB100 & 0.097 & 0.426 & 0.227 \\
gr-SB80M20 & 0.091 & 0.426 & 0.214 \\
gr-M80SB20 & 0.093 & 0.426 & 0.219 \\
ch-M100 & 0.076 & 0.350 & 0.216 \\
ch-SB100 & 0.098 & 0.482 & 0.204 \\
ch-SB80M20 & 0.062 & 0.252 & 0.244 \\
\hline
\end{tabular}

to $\mathrm{C}=\mathrm{O}$ vibrations of carboxylic groups (band $\mathrm{B}$ ). However, the FTIR and DRIFT spectra differed in the intensity of the absorption bands A and B (Fig. 1). The intensity of the $\mathrm{CH}-$ and $\mathrm{C}=\mathrm{O}$-bands was significantly $(\mathrm{p}<0.05)$ higher in the DRIFT spectra than in the transmission FTIR spectra. In comparison to the transmission FTIR spectra, the DRIFT spectra did not show the Si-O-Si band at a wavenumber of around $1000 \mathrm{~cm}^{-1}$ (band $\mathrm{C}$ ).

The DRIFT spectra of the soil-AD-mixtures showed significantly higher absorption intensities of the $\mathrm{CH}$-band (band A) as compared to the one of the unamended control C. This was not found for the FTIR spectra. The comparison between the spectra showed higher absorption intensity at $\mathrm{B}$ and $\mathrm{A}$ bands as well as an increasing $\mathrm{CH} / \mathrm{C}=\mathrm{O}$-ratio (A/B) of the soil-AD-mixtures from ground as compared to that from chopped IS.
The DRIFT spectra of the particle intact (PI) soil-digestate-mixture samples are similar to those from ground and chopped IS (graphic not shown). The intensity of the $\mathrm{CH}$ absorption band (B) was higher for the soil-AD-mixtures compared to the one of the unamended control soil $\mathrm{C}$.

The intensity of the A and B bands of the DRIFT (G) spectra was statistically higher $(\mathrm{p}<0.05)$ compared to the absorption intensity of the $\mathrm{CH}$ - and $\mathrm{C}=\mathrm{O}$-bands of the FTIR (G) spectra (Table 4). In contrast to these former findings offered the absorption intensity of the A- and B-bands of the PI intact samples up to threefold higher absorption intensities of A- and B-bands compared to the spectra of the (G) samples, which was not least represented by the A/B ratio of the samples. However, in the FTIR $(G)$ spectra, the gr-M80SB20 sample exhibited the highest intensity of the $\mathrm{CH}-$ band while in the DRIFT (G and PI) spectra gr-M100 showed the highest intensity of the CH-band (Table 4).

The control soil possessed a $\mathrm{CA}<90^{\circ}$ and hence it could be classified as hydrophilic (Table 4). The soil-ADmixtures showed higher CA values whereby the CA values were slightly higher for the mixtures with $\mathrm{AD}$ from ground (88.9 to 91.5) as compared to those from chopped IS (81.1 to 91.0) (Table 4), except for gr-SB100, which exhibited similar CA values for the mixtures from AD with chopped and ground IS.

The CA values were positively correlated (but not significantly) with the intensity of the absorption band $\mathrm{A}$ and with the $\mathrm{A} / \mathrm{B}$ ratio of the ground and particle intact samples, respectively (Fig. 2). The A/B ratio determined from the FTIR and DRIFT spectra of the ground mixtures showed a better correlation with the CA compared to the A-band (Fig. 2a, b, d, e). The correlation between both, the A-band and the $\mathrm{A} / \mathrm{B}$ ratio was higher in the DRIFT spectra of the 
a

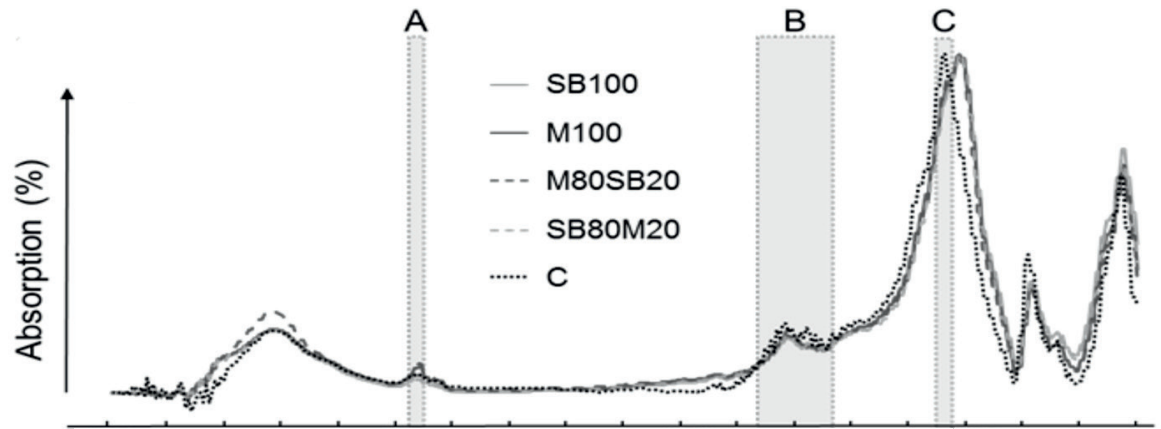

b

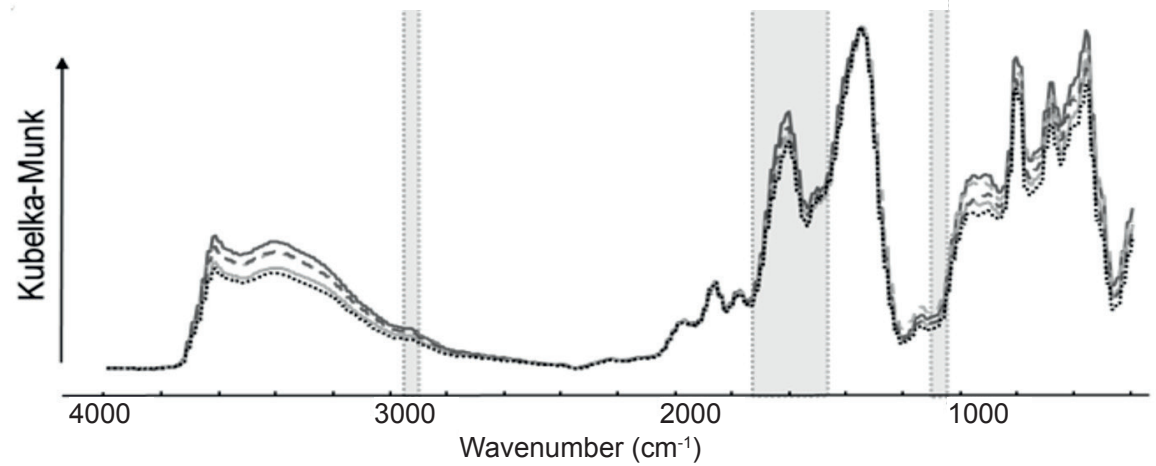

Fig. 1. FTIR (a) and DRIFT (b) spectra (ground samples) of digestate-soil mixtures (SB100: 100\% of sugar beet; M100: 100\% of maize; SB80M20: $80 \%$ of sugar beet and 20\% of maize; M80SB20: $80 \%$ of maize and 20\% of sugar beet) derived from ground input substrates.

T a b l e 4. Intensity of $\mathrm{CH}$ and $\mathrm{C}=\mathrm{O}$ band in FTIR and DRIFT spectra of ground (G) and particle intact (PI) samples ( $\mathrm{n}=4)$ as well as the contact angle $(\mathrm{CA})\left[^{\circ}\right]$ of soil-AD-mixtures $(n=6)$ and untreated soil $(\mathrm{C})$

\begin{tabular}{|c|c|c|c|c|c|c|c|c|c|c|}
\hline \multirow[b]{2}{*}{ Amendment } & \multicolumn{3}{|c|}{ FTIR (G) } & \multicolumn{3}{|c|}{ DRIFT (G) } & \multicolumn{3}{|c|}{ DRIFT (PI) } & \multirow[b]{2}{*}{ CA } \\
\hline & $\mathrm{CH}$ & $\mathrm{C}=\mathrm{O}$ & $\begin{array}{l}\mathrm{CH} / \\
\mathrm{C}=\mathrm{O}\end{array}$ & $\mathrm{CH}$ & $\mathrm{C}=\mathrm{O}$ & $\begin{array}{l}\mathrm{CH} / \\
\mathrm{C}=\mathrm{O}\end{array}$ & $\mathrm{CH}$ & $\mathrm{C}=\mathrm{O}$ & $\begin{array}{l}\mathrm{CH} / \\
\mathrm{C}=\mathrm{O}\end{array}$ & \\
\hline gr-M100 & $0.034 b$ & $0.152 b$ & $0.223 b$ & $4.003 b$ & $21.589 \mathrm{a}$ & $0.185 \mathrm{a}$ & $11.647 \mathrm{a}$ & $78.255 b$ & $0.149 \mathrm{a}$ & $89.8 \mathrm{a}$ \\
\hline gr-SB100 & $0.024 b$ & $0.107 \mathrm{~b}$ & $0.228 b$ & $3.362 b$ & $19.612 \mathrm{a}$ & $0.171 \mathrm{a}$ & $11.621 \mathrm{a}$ & $67.596 a$ & $0.172 \mathrm{a}$ & $91.5 \mathrm{a}$ \\
\hline gr-SB80M20 & $0.019 \mathrm{a}$ & $0.146 b$ & $0.133 b$ & $3.409 \mathrm{~b}$ & $18.670 \mathrm{a}$ & $0.183 \mathrm{a}$ & $10.474 a$ & $64.005 \mathrm{a}$ & $0.164 \mathrm{a}$ & $90.2 \mathrm{a}$ \\
\hline gr-M80SB20 & $0.042 \mathrm{~b}$ & $0.107 b$ & $0.390 \mathrm{~b}$ & $3.862 b$ & $21.221 \mathrm{a}$ & $0.182 \mathrm{a}$ & $9.087 \mathrm{a}$ & $53.034 \mathrm{a}$ & $0.171 \mathrm{a}$ & $88.9 \mathrm{a}$ \\
\hline ch-M100 & $0.013 \mathrm{a}$ & $0.164 b$ & $0.081 \mathrm{a}$ & $2.807 \mathrm{a}$ & $16.360 \mathrm{a}$ & $0.172 \mathrm{a}$ & $10.792 \mathrm{a}$ & $74.370 \mathrm{~b}$ & $0.145 \mathrm{a}$ & $81.1 \mathrm{a}$ \\
\hline ch-SB100 & $0.007 \mathrm{a}$ & $0.082 \mathrm{a}$ & $0.087 \mathrm{a}$ & $2.755 \mathrm{a}$ & $17.207 \mathrm{a}$ & $0.160 \mathrm{a}$ & $11.242 \mathrm{a}$ & 59.999a & $0.187 \mathrm{a}$ & $91.0 \mathrm{a}$ \\
\hline ch-SB80M20 & $0.009 a$ & $0.115 b$ & $0.082 \mathrm{a}$ & $2.942 \mathrm{a}$ & $17.202 \mathrm{a}$ & $0.171 \mathrm{a}$ & $11.977 \mathrm{a}$ & $74.723 b$ & $0.160 \mathrm{a}$ & $87.4 a$ \\
\hline ch-M80SB20 & $0.009 a$ & $0.118 b$ & $0.073 \mathrm{a}$ & $2.811 \mathrm{a}$ & $16.813 \mathrm{a}$ & $0.167 \mathrm{a}$ & $10.957 \mathrm{a}$ & $66.127 \mathrm{a}$ & $0.166 a$ & $89.6 a$ \\
\hline $\mathrm{C}$ & $0.007 \mathrm{a}$ & $0.063 \mathrm{a}$ & $0.063 \mathrm{a}$ & $2.808 \mathrm{a}$ & $18.194 \mathrm{a}$ & $0.154 \mathrm{a}$ & $8.460 \mathrm{a}$ & $51.548 \mathrm{a}$ & $0.164 \mathrm{a}$ & $79.0 \mathrm{a}$ \\
\hline
\end{tabular}

Different letters $(a b)$ indicate statistically significant differences $(\mathrm{p}<0.05)$ of the functional groups of digestates in comparison to the control.

ground samples compared to the transmission FTIR spectra. The correlation of the intensity of the A-band as well as the $\mathrm{A} / \mathrm{B}$ ratio was best using intact particle samples (Fig. $2 \mathrm{c}$ and $\mathrm{f}$ ). The spectra of the PI exhibited a higher correlation between $\mathrm{CA}$ and the intensity of the A-band compared to the A/B-ratio.

\section{DISCUSSION}

Soil organic matter is characterized by the amount of particulate organic matter, organo-mineral complexes (Leue et al., 2013), humic acids, the content of functional groups $(\mathrm{CH}$ and $\mathrm{C}=\mathrm{O})$ and their spatial conformation of organic molecules on the microscale (Morrison and Boyd, 1983). 

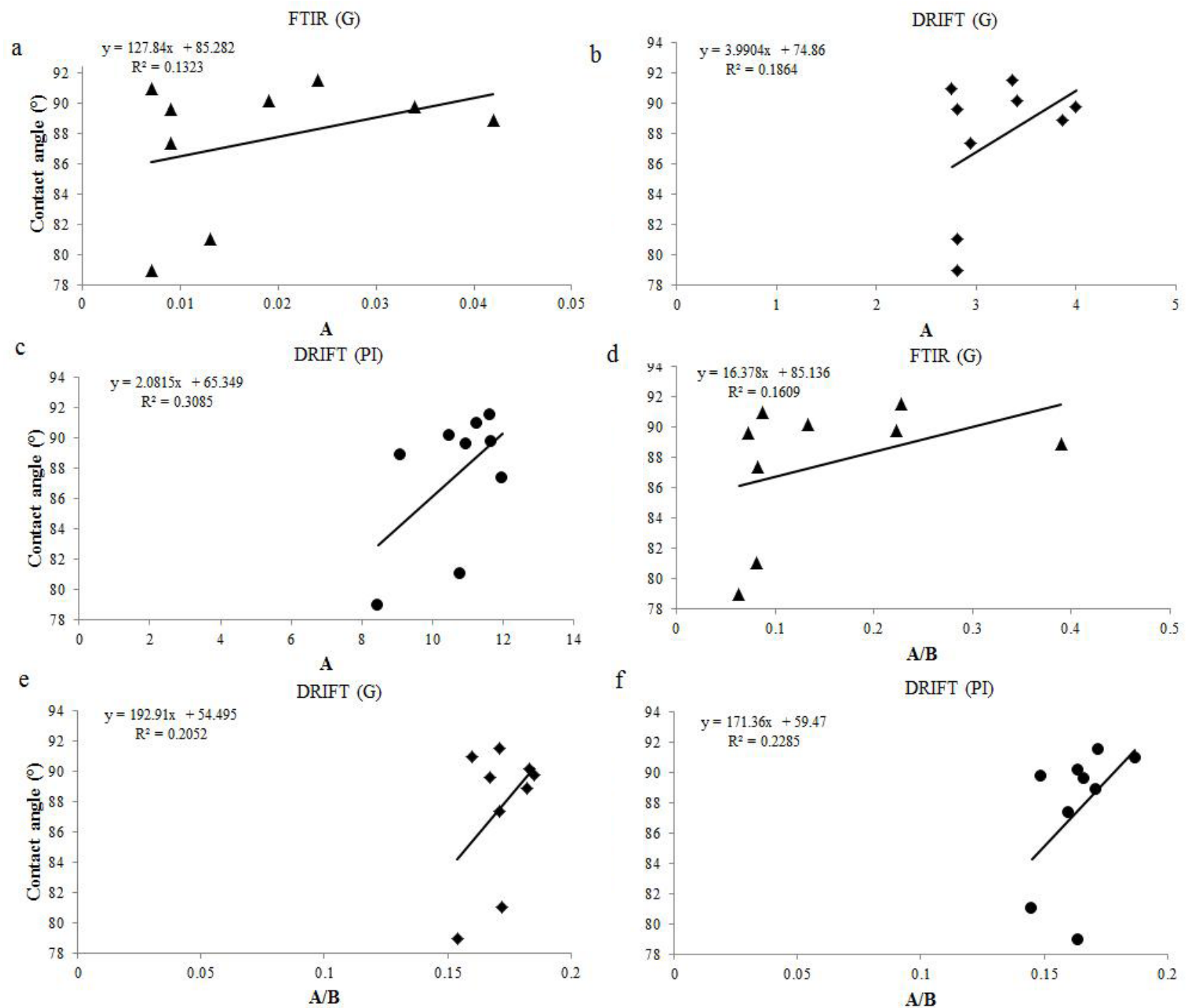

f

DRIFT (PI)

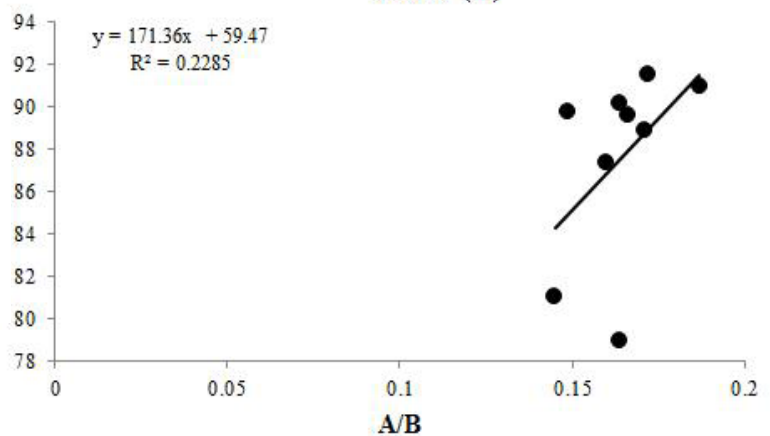

Fig. 2. CA $\left(^{\circ}\right) v s$. intensity of absorption band A determined from: a - FTIR, b - DRIFT of ground (G) and c - DRIFT spectra of particle intact samples and $\mathrm{CA}\left({ }^{\circ}\right)$ vs. A/B ratio determined from $\mathrm{d}-\mathrm{FTIR}, \mathrm{e}-\mathrm{DRIFT}$ of ground $(\mathrm{G})$ and $\mathrm{f}-\mathrm{DRIFT}$ spectra of particle intact samples.

The organic material of anaerobic digestates contains great amounts of amphiphilic components like long-chained fatty acids, which are transferred to the soil matrix after application (Täumer et al., 2005); it can flow into pore spaces or may surround mineral particles. The effect of this coating on the soil is mainly determined by the ratio of hydrophobic $\mathrm{CH}$-bands to hydrophilic $\mathrm{C}=\mathrm{O}$-bands, which in term has major implications for the wetting behaviour of mineral particles (Ellerbrock and Gerke, 2004). The FTIR and DRIFT spectra of the soil-AD-mixtures indicate a change in the composition of SOM after digestate amendment: the amount of hydrophobic CH-groups is higher as compared to the unamended soil reflected by a more pronounced peak at a wavenumber of 2920 and $2860 \mathrm{~cm}^{-1}$. This may be explained by a supply of hydrophobic functional groups contained in the ADs. This is in accordance with Capriel et al. (1997), who assessed a close relationship between $\mathrm{CH}$ content and soil hydrophobicity. With an increasing amount of CH-groups determined by FTIR and DRIFT the wettability of the soil-AD-mixtures decreases.

The $\mathrm{CH} / \mathrm{C}=\mathrm{O}$ ratio, which is also assumed to reflect the potential wettability of soil samples (Ellerbrock et al., 2005), can just be partly related to the wettability of soilAD-mixtures investigated here. Ellerbrock et al. (2009) used FTIR spectroscopy to investigate the ratio of hydrophobic $\mathrm{CH}$-bands (A) to hydrophilic $\mathrm{C}=\mathrm{O}$-bands (B) in the SOM and found that the lower values of the $\mathrm{A} / \mathrm{B}$ ratio indicate more hydrophilic conditions of the OM, while the 
hydrophobicity increases. They concluded that the hydrophobic functional $\mathrm{CH}$-groups seemed to be less effective in reducing soil wettability. These findings are consistent for the soil-AD-mixtures from the finely ground samples investigated with FTIR and DRIFT spectroscopy. The highest wettability of the soil-AD-mixture ch-M100 from the ground samples does not show the lowest $\mathrm{A} / \mathrm{B}$ ratio and, at the same time, the lowest wettability of the ground samples from the soil-AD-mixtures (gr-SB100 and ch-SB100) does not exhibit the highest proportion from hydrophobic $\mathrm{CH}$-bands to hydrophilic $\mathrm{C}=\mathrm{O}-$ bands. However, the $\mathrm{PI}$ samples show compliance of the wettability and the A/B ratio of the soil-AD-mixtures. Based on these results, the composition of the functional groups of the organic matter cannot be considered as the only factor to derive the actual hydrophobicity of the soil after AD amendment.

Besides the qualitative composition of the $\mathrm{OM}$, another explanation for variances in soil wettability may be the quantity of organic compounds and their spatial arrangement in the pore space, which cannot be detected with the FTIR or DRIFT spectra. Depending on the soil water content, the organic compounds - consisting of a hydrophobic carbon backbone and a hydrophilic functional group may change their orientation in the pore space when the water content falls below critical water content (GonzálesPeñaloza et al., 2013). In a dry surrounding, the hydrophilic groups are attracted and the hydrophobic backbones are arranged around the hydrophilic centre, which results in more hydrophobic conditions. However, although the soilAD-mixture samples are air-dried, such reorientation of the organic molecules is not reflected in a noticeably increasing contact angle. The extent of the hydrophobic effect is further dependent on the soil texture since the loamy sand contains great amounts of clay particles, which exhibit a considerable greater specific surface area with reactive binding places (Caravaca et al., 2001). The additional supply of functional groups with the ADs seems to be sufficient to cover the multitude of binding places on the clay particle surfaces, as a result the impact of the functional groups on hydrophobization is less intensive. Gerin et al. (2003) found that for fine-textured soils, a dilution effect of the SOM might occur due to the relatively large surface areas of the soil particles, which results in a thin and less effective coating of organic compounds on the particle surface.

The FTIR and DRIFT spectra can be only detected from air-dried soil-AD-mixtures and freeze-dried ADs. As a result, the findings from this study can be transferred to field conditions in the case of a dry period but are not transferable to moist soil conditions after rainfall. For the used methods (spectroscopic technique as well as the measurement of the contact angle), homogenized soil was required. Thus, after occurrence of wetting and drying cycles in the field and subsequent soil structure formation, the results may not be transferable to field conditions any more.
Thus, we can conclude that the situation observed in the laboratory cannot be projected to field conditions one to one. Nevertheless, the measurements are a first attempt to estimate the impact of ADs on soil wetting properties on the microscale.

The analysis of the organic functional groups using FTIR and DRIFT spectroscopy shows only very small differences, but the pre-treatment of the samples seems to be the decisive factor. The PI samples exhibit the best correlation between the A/B ratio as well as the height of the A-band compared to the finely ground samples. Nevertheless, the content of hydrophobic $\mathrm{CH}$ bands of the PI samples reflects better the actual hydrophobicity of the soil compared to the A/B ratio. Reeves et al. (2005) assumed that grinding of the particles might influence the spectra of the intensity of the adsorption bands. Amelung et al. (2002) suggested that grinding of the particles destroyed the mineral particles as well as the organic coating. These offers further mineral surfaces without any organic compounds. Consequently, the organic compounds are diluted due to the crushing process and the spectra represent more the mineral nuclei than the organic compounds of the coating. This is confirmed by the missing Si-O-Si-band (band C) in the DRIFT spectra of the PI samples compared to the FTIR spectra. Since the ground soil-AD-mixtures exhibit low values for the A- and B-bands, the absorption intensity of the $\mathrm{CH}$ - and $\mathrm{C}=\mathrm{O}$ bands of the PI samples are substantially higher. This indicates that mainly the organic coating of the PI particles was recorded, while the proportion of the silicate particle exceeds the quantity of the organic compounds. The ground samples from FTIR reflect both the surface consisting of organic compounds and the quartz core (Leue et al., 2010), while the PI samples from DRIFT represent proportionately the coating surrounding the mineral core. Previous studies from Ellerbrock and Gerke (2004) confirmed already that the KBr-technique of FTIR spectroscopy was not suitable to determine primarily the outer surface of soil particles.

\section{CONCLUSIONS}

1. The determination of hydrophobic and hydrophilic functional groups of organic matter contained in the anaerobic digestates using Fourier transform infrared and diffuse reflectance infrared Fourier transform is suitable to obtain information about the potential wettability of the organic compounds but is not transferable to actual wettability of soil in any case.

2. The applicability of Fourier transform infrared and diffuse reflectance infrared Fourier transform spectroscopy of differently mechanically pre-treated samples were tested in this study to explain the change of the contact angle of the samples after anaerobic digestates application. Differences in the composition of the organic matter could be detected for the soil-anaerobic digestates-mixtures compared to the unamended control for the ground and particle intact samples. 
3. For the particle intact samples, the ratio of potentially hydrophobic groups and potentially hydrophilic and the quantity of potentially hydrophobic $\mathrm{CH}$-bands are found to correlate best with the actual wettability of the soil, whereas the utility of the A-bands is more suitable to evaluate the anaerobic digestates induced reduced soil wettability.

4. The ground samples do not reflect the actual wettability in all cases due to a high dilution effect of the organic functional groups with the silicate core.

5. It can be summarized that the composition of anaerobic digestates organic matter will be best achieved by evaluating particle intact samples using the diffuse reflectance infrared Fourier transform technique. However, the microtopography of the particle intact samples remains unconsidered applying diffuse reflectance infrared Fourier transform spectroscopy and has to be taken into account in further investigations. At present, it is not possible to determine only the hydrophilic functional groups by considering the hydrophilic bands, but also further organic components which cannot be separated from the hydrophilic bands. This could therefore be a solution to evaluate the potential wettability of the organic matter based on the ratio of the hydrophobic bands and the silicium band according to the approach of Bernier et al. (2013).

\section{REFERENCES}

Alburquerque J.A., de la Fuente C., Campoy M., Carrasco L., Najera I., Baixauli C., Caravaca F., Roldan A., Cegarra J., and Bernal M.P., 2012. Agricultural use of digestate for horticultural crop production and improvement of soil properties. European J. Agronomy, 43, 119-128.

Amelung W., Kaiser K., Kammerer G., and Sauer G., 2002. Organic carbon at soil particle surfaces - Evidence from $\mathrm{X}$-ray photoelectron spectroscopy and surface abrasion. Soil Sci. Soc. Am. J., 66, 1526-1530.

Bachmann J., Woche S.K., Goebel M.-O., Kirkham M.B., and Horton R., 2003. Extended methodology for determining wetting properties of porous media. Water Res., 39, 1353-1359.

Bernier M.-H., Levy G.J., Fine P., and Borisover M., 2013. Organic matter composition in soils irrigated with treated wastewater: FT-IR spectroscopic analysis of bulk soil samples. Geoderma, 209-210, 233-240.

Boyd S.A., Sommers L.E., and Nelson D.W., 1980. Changes in the Humic-acid fraction of soil resulting from sludge application. Soil Sci. Soc. Am. J., 44, 1179-1186.

Capriel P., Beck T., Borchert H., Gronholz J., and Zachmann G., 1995. Hydrophobicity of the organic-matter in arable soils. Soil Biology and Biochemistry, 27, 1453-1458.

Capriel P., Harter P., and Stephenson D., 1992. Influence of management on the organic-matter of a mineral soil. Soil Sci., 153,122-128.

Caravaca F., Lax A., and Albaladejo J., 2001. Soil aggregate stability and organic matter in clay and fine silt fractions in urban refuse-amended semiarid soils. Soil Sci. Soc. Am. J., 1235-1238.
Celi L., Schnitzer M., and Negre M., 1997. Analysis of carboxyl groups in soil humic acids by a wet chemical method, Fouriertransform infrared spectrophotometry, and solution-state carbon-13 nuclear magnetic resonance. A comparative study. Soil Sci., 162, 189-197.

Demyan M.S., Rasche F., Schulz E., Breulmann M., Muller T., and Cadisch G., 2012. Use of specific peaks obtained by diffuse reflectance Fourier transform mid-infrared spectroscopy to study the composition of organic matter in a Haplic Chernozem. European J. Soil Sci., 63,189-199.

Ellerbrock R.H. and Gerke H.H., 2004. Characterizing organic matter of soil aggregate coatings and biopores by Fourier transform infrared spectroscopy. European J. Soil Sci., 55, 219-228.

Ellerbrock R.H., Gerke H.H., Bachmann J., and Goebel M.O., 2005. Composition of organic matter fractions for explaining wettability of three forest soils. Soil Sci. Soc. Am. J., 69, 57-66.

Ellerbrock R.H. and Kaiser M., 2005. Stability and composition of different soluble soil organic matter fractions - evidence from delta C-13 and FTIR signatures. Geoderma, 128, 28-37.

Ellerbrock R.H., Gerke H.H., and Böhm C., 2009. In situ DRIFT characterization of organic matter compositions on soil structural surfaces. Soil Sci. Soc. Am. J., 73, 531-540.

Franco C.M.M., Clarke P.J., Tate M.E., and Oades J.M., 2000. Hydrophobic properties and chemical characterisation of natural water repellent materials in Australian sands. J. Hydrol., 231, 47-58.

Gerin P.A., Genet M.J., Herbillon A.J., and Delvaux B., 2003. Surface analysis of soilmaterial by X-ray photoelectron spectroscopy. European J. Soil Sci., 54, 589-603.

Gerzabek M.H., Pichlmayer F., Kirchmann H., and Haberhauer G., 1997. The response of soil organic matter to manure amendments in a long-term experiment at Ultuna, Sweden. European J. Soil Sci., 48, 273-282.

Gonzáles-Peñaloza F.A., Zavala L.M., Jordán A., Bellinfante N., Bárcenas-Moreno G., Mataix-Solera J., Granged A.J.P., Granja-Martins F.M., and Neto-Paixão H.M., 2013. Water repellency as conditioned by particle size and drying in hydrophobized sand. Geoderma, 209-210, 31-40.

Günzler H., and Böck H., 1990. IR-Spektroskopie. Verlag Chemie, Weinheim, Germany.

Haberhauer G. and Gerzabek M.H., 1999. Drift and transmission FT-IR spectroscopy of forest soils: an approach to determine decomposition processes of forest litter. Vibrational Spectroscopy, 19, 413-417.

Hartmann P.M., 2008. Bodenphysikalische Eigenschaften, Benetzbarkeiten und Wasserhaushalt von Waldböden unter Flugascheeinfluss. Dissertation, University of Kiel, Kiel, Germany.

Hurraß J. and Schaumann G.E., 2006. Properties of soil organic matter and aqueous extracts of actually water repellent and wettable soil samples. Geoderma, 132, 222-239.

Leue M., Ellerbrock R.H., and Gerke H.H., 2010. DRIFT mapping of organic matter composition at intact soil aggregate surfaces. Vadose Zone J., 9, 317-324. 
Leue M., Gerke H.H., and Ellerbrock R.H., 2013. Millimetrescale distribution of organic matter composition at intact biopore and crack surfaces. European J. Soil Sci., 64, 757-769.

McDowell M.L., Bruland G.L., Deenik J.L., Grunwald S., and Knox N.M., 2012. Soil total carbon analysis in Hawaiian soils with visible, near-infrared and mid-infrared diffuse reflectance spectroscopy. Geoderma, 189, 312-320.

Morrison R.T. and Boyd R.N., 1983. Lehrbuch der organischen Chemie. Verlag Chemie, Weinheim, Germany.

Negre M., Vindrola D., Spera S., Ferraris L., and Gennari M., 2002. Effect of the chemical composition of soil humic acids on their viscosity, surface pressure, and morphology. Soil Sci., 167, 636-651.

Reeves J.B., Francis B.A., and Hamilton S.K., 2005. Specular reflection and diffuse reflectance spectroscopy of soils. Applied Spectroscopy, 59, 39-46.

Reeves J.B., McCarty G.W., and Reeves V.B., 2001. Midinfrared diffuse reflectance spectroscopy for the quantitative analysis of agricultural soils. J. Agric. Food Chemistry, 49, 766-772.

Révéille V., Mansuy L., Jarde E., and Garnier-Sillam T., 2003. Characterisation of sewage sludge-derived organic matter: lipids and humic acids. Organic Geochemistry, 34, 615-627.
Schlichting E., Blume H.-P., and Stahr K., 1995. Bodenkundliches Praktikum: Eine Einführung in pedologisches Arbeiten für Ökologen, insbesondere Land- und Forstwirte und für Geowissenschaftler. 2nd, revised edition, Vol. 81. Berlin, Wien: Blackwell-Wissenschafts-Verlag.

Sørensen P. and Møller H.B., 2009. Fate of nitrogen in pig and cattle slurries applied to the soil-crop system. In: Anaerobic digestion: Opportunities for agriculture and environment (Eds F. Adani et al.). DiProVe University of Milan, Milan, Italy.

Tatzber M., Stemmer M., Spiegel H., Katzlberger C., Haberhauer G., and Gerzabek M.H., 2007. An alternative method to measure carbonate in soils by FT-IR spectroscopy. Environmental Chemistry Letters, 5, 9-12.

Täumer K., Stoffregen H., and Wessolek G., 2005. Determination of repellency distribution using soil organic matter and water content. Geoderma, 125, 107-115.

Tremblay L. and Gagné J.P., 2002. Fast quantification of humic substances and organic matter by direct analysis of sediments using DRIFT spectroscopy. Analytical Chemistry, 74, 2985-2993. 